\title{
Collaboration between pharmacists and general practitioners in the health care system in the Islamic Republic of Iran
}

\author{
F. Hashemian ", F. Emadi ${ }^{1}$ and E. Roohi ${ }^{7}$
}

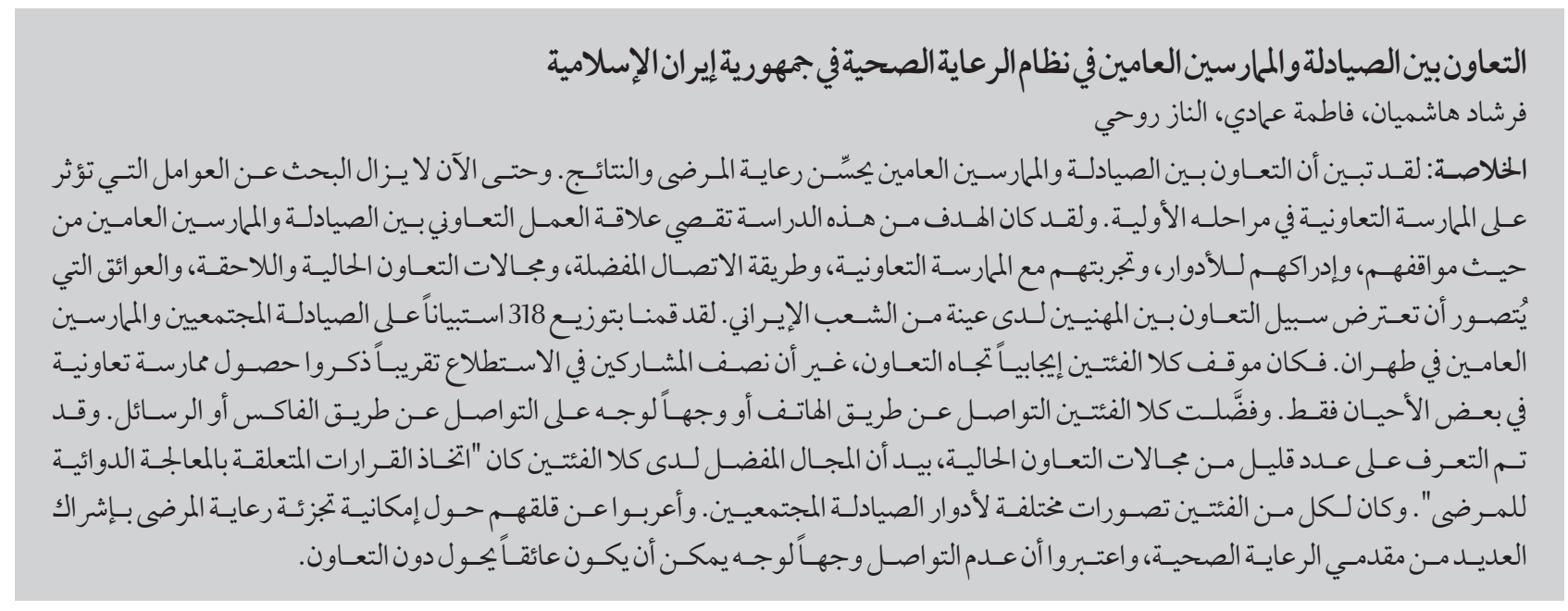

ABSTRACT Collaboration between pharmacists and general practitioners (GPs) has been shown to enhance patient care and outcomes. The aim of the present study was to investigate the collaborative working relationship between pharmacists and GPs in terms of their attitudes, role perceptions, experience with collaborative practice, preferred method of communication, areas of current and further collaboration, and perceived barriers to interprofessional collaboration in a sample of the Iranian population. We distributed 318 questionnaires to community pharmacists and GPs in Tehran. Both groups had a positive attitude towards collaboration; however, about half the respondents reported only occasional collaborative practice. Both groups preferred communication by telephone or face-toface communication by fax or letter. Few current areas of collaboration were identified; however, an area favoured by both groups was "decision-making for patients' pharmacotherapy". The two groups expressed concern about possible fragmentation of patient care with the involvement of multiple health care providers, and perceived lack of face-to-face communication as a possible barrier to collaboration.

Collaboration entre pharmaciens et médecins généralistes dans le système de soins de santé en République islamique d'Iran

RÉSUMÉ II a été démontré que la collaboration entre les pharmaciens et les médecins généralistes était un facteur d'amélioration des soins dispensés aux patients ainsi que de leur état de santé. La présente étude avait pour objectif d'examiner la collaboration professionnelle entre pharmaciens et médecins généralistes dans un échantillon de la population iranienne en termes d'attitudes, de perception des rôles, d'expérience de collaboration, de méthode de communication privilégiée, de domaines de la collaboration actuelle et future, et de barrières perçues en matière de collaboration interprofessionnelle. Nous avons distribué 318 questionnaires aux pharmaciens communautaires et médecins généralistes de Téhéran. Les deux groupes étaient favorables à la collaboration, mais près de la moitié des participants ont rapporté n'entretenir des relations de collaboration que sur une base occasionnelle. Les deux groupes ont déclaré préférer une communication par téléphone ou en face à face que parfax ou courrier. Peu de domaines faisant l'objet d'une collaboration actuelle ont été identifiés. Cependant, les deux groupes avaient pour domaine de prédilection « la prise de décision concernant la pharmacothérapie des patients ». Les deux groupes se sont dit préoccupés par une possible fragmentation des soins dispensés aux patients du fait de l'apparition de multiples prestataires de soins de santé, et percevaient le manque de communication en face à face comme une barrière potentielle à la collaboration. 


\section{Introduction}

Today, interprofessional collaboration is seen as an integral part of the practice of medicine and even of medical education (1). Collaborative working relationships promote the provision of pharmacotherapy management services, disease state management and other patient care services (2). "Interprofessionality" is defined as the development of cohesive practice among professionals in different fields, which enables them to reflect upon and find ways of practising that provide an integrated answer to clients' and patients' needs. This involves continuous knowledge-sharing among professionals to optimize patient care and improve their outcomes (3). Pharmacists and GPs have increasingly been encouraged to become involved in interprofessional collaboration in order to enhance patient care and achieve therapeutic goals (4). A number of collaborative experiences between pharmacists and physicians have been reported, and the benefits of such collaboration have been well documented (5-12).

To date, research has focused on the effects of GP-pharmacist collaboration on patient care and outcomes. Another approach might be to study factors that influence collaborative practice, which could provide insight for future interprofessional care and research on models of interprofessional practice. One such factor is the attitude towards collaboration, as it may influence the degree to which GPs and pharmacists collaborate (4). The attitudes of pharmacists were found to be significantly correlated with care-providing functions (13). Another factor is perceptions of the role of community pharmacists (14). In recent years, the role has evolved from the traditional one of dispensing medicines to a more clinical role $(15,16)$, and there may be certain skills and expertise that are not apparent to both types of professionals. Differing role perceptions are likely to result in barriers to interprofessional collaboration (15); identification and removal of perceived interprofessional barriers between pharmacists and GPs is essential for establishing collaboration (17).

To our knowledge, collaborative practice between pharmacists and general practitioners has not previously been studied in the Islamic Republic of Iran or most probably in Asia. The aim of this study was therefore to investigate collaborative working relationships between pharmacists and GPs in terms of their attitudes, role perceptions, experiences with collaborative practice, preferred method of communication for collaborative practice, areas of current and potential further collaboration and perceived barriers in a sample of the Iranian population.

\section{Methods}

A comprehensive literature search was conducted to identify studies on GPpharmacist collaborative practice. The survey questions used in a study on pharmacists' and physicians' views on collaborative practice in a community pharmaceutical care project (18) were translated into Persian with the authors' permission (Dr Deborah Kelly, personal communication), and the translated questions were tested for content and face validity by 10 expert clinical pharmacists and physicians. All the survey questions were pilot-tested in a sample of 45 expert community pharmacists and general physicians, and the reliability of the questionnaire was calculated to be 0.87 with Cronbach's alpha. Seven survey questions ( 43 items) were used to measure respondents' views on different aspects of interprofessional collaboration between GPs and pharmacists.

\section{Data collection}

Pharmacists (including those with experience of practising as community pharmacists) and physicians attending four continuous medical education programmes between February and August 2014 were invited to participate in the study, and 318 questionnaires were distributed, covering various aspects of interprofessional collaboration, demographic data (including gender, age and educational), number of years since graduation, community size and any academic affiliation.

The study protocol was approved by the ethics committee at Islamic Azad University, Pharmaceutical Sciences Branch (ID Number: 863).

\section{Data analysis}

The data were analysed with SPSS 21.0 software. Descriptive statistics were used to calculate results for each group separately, and Spearman rank correlations were used in order to identify between age, gender, education, community size and university affiliation and responses concerning attitudes, role perceptions, experience with collaborative practice, preferred method of communication, areas of current and possible further collaboration and perceived barriers to interprofessional collaboration. $P$ values less than 0.05 were assumed to be significant.

\section{Results}

Of the 318 survey questionnaires distributed, 231 were completed, for a response rate of $72.6 \%$. The demographic characteristics of the respondents are summarized in Table 1.

In both respondent groups, significant relations were found between age, gender, community size and university affiliation and certain aspects of interprofessional collaboration (Table 2). Significant relations were also found between the university degree (PharmD or $\mathrm{MD})$ and all the role perceptions investigated $(P=0.000)$ expect for the role of pharmacists in dispensing prescriptions. Significant relations were found between current collaborative 


\begin{tabular}{|c|c|c|}
\hline Characteristic & $\begin{array}{l}\text { Pharmacists } \\
(n=132)\end{array}$ & $\begin{array}{c}\text { General practitioners } \\
\qquad(n=99)\end{array}$ \\
\hline \multicolumn{3}{|l|}{ Sex } \\
\hline Female & $110(83.3 \%)$ & $54(54.5 \%)$ \\
\hline Male & $22(16.7 \%)$ & $45(45.5 \%)$ \\
\hline \multicolumn{3}{|l|}{ Age (years) } \\
\hline $20-29$ & $80(60.6 \%)$ & $26(26.3 \%)$ \\
\hline $30-39$ & $31(23.5)$ & $36(36.4 \%)$ \\
\hline $40-49$ & $8(6.1 \%)$ & $31(31.3 \%)$ \\
\hline$>50$ & $13(9.8 \%)$ & $6(6.1 \%)$ \\
\hline \multicolumn{3}{|l|}{ Number of years since graduation } \\
\hline$<10$ & $106(80.3 \%)$ & $58(58.6 \%)$ \\
\hline $10-19$ & $10(7.6 \%)$ & $34(34.3 \%)$ \\
\hline $20-29$ & $6(4.5 \%)$ & $2(2.0 \%)$ \\
\hline$>30$ & $10(7.6 \%)$ & $5(5.1 \%)$ \\
\hline \multicolumn{3}{|l|}{ Community size } \\
\hline Small town (2000-1 000000 population) & $21(15.9 \%)$ & $25(25.3 \%)$ \\
\hline City (> 1000000 population) & $111(84.1 \%)$ & $74(74.7 \%)$ \\
\hline \multicolumn{3}{|l|}{ University affiliation } \\
\hline No & $111(84.1 \%)$ & $75(75.8 \%)$ \\
\hline Yes & $21(15.9 \%)$ & $24(24.2 \%)$ \\
\hline
\end{tabular}

practice in modifying patients' pharmacotherapy, dose adjustment, managing side-effects of medication, patient counselling and improving patient adherence.

Attitudes towards collaborative practice were similar in the two respondent groups. The proportion of pharmacists who reported having tried to collaborate with GPs in order to enhance patient care was $14.6 \%$, whereas only $12.4 \%$ of GPs reported attempted collaboration. Almost half of each group agreed that collaboration between health care professionals enhances patient care, and one third of pharmacists and one fourth of GPs believed that collaboration between their professions would enhance patient care.

Nearly half of each group reported having had occasional collaboration with their counterparts (47.0\% of pharmacists and $40.4 \%$ of GPs), while $32.6 \%$ of pharmacists and $28.3 \%$ of GPs reported having never or rarely experienced collaborative practice; $6.1 \%$ of pharmacists and $11.1 \%$ of GPs reported having always collaborated with their counterparts, and $14.3 \%$ of pharmacists and $20.2 \%$ of GPs reported frequent experience with collaboration.

The preferred method of communication for collaborative practice for both groups was by telephone or face to face rather than by fax or letter. Communication by telephone was preferred by $57.1 \%$ of pharmacists and $31.6 \%$ of GPs, whereas $42.9 \%$ of GPs and $26.2 \%$ of pharmacists preferred face-to-face communication. Only $7.1 \%$ of pharmacists and $12.2 \%$ of GPs reported letterwriting to be their preferred method.

When pharmacists were asked whether the tasks cited in Table 3 should be identified as components of the role of community pharmacists, there was a high level of agreement that activities such as "assisting patients in selecting over-the-counter medication", "patient counselling", "helping to manage medication side-effects" and "helping to manage drug interactions" should be part of their role. They also agreed that roles such as "dispensing prescriptions" and "helping with medication insurance and reimbursement issues" were not part of the role of community pharmacists. A large majority of GPs perceived none of the roles listed in Table 3 as those of a community pharmacist.

In response to the question about areas in which they currently collaborate, both groups agreed that there is currently little collaboration in all areas. Both groups reported that the most frequent collaboration is to "manage drug interactions", "provide patient counselling" and "manage side-effects of medications”.

When asked about possible areas of future collaboration (Table 4), pharmacists were more willing than GPs to collaborate in various areas. Both groups were willing to collaborate in decisionmaking on patients' pharmacotherapy and management of drug interactions.

The pharmacists and GPs agreed on perceived barriers to collaborative practice. Both groups expressed 


\begin{tabular}{|c|c|c|c|c|}
\hline & \multicolumn{2}{|c|}{ Pharmacists } & \multicolumn{2}{|c|}{ GPs } \\
\hline & $\boldsymbol{P}$ & $\boldsymbol{R}$ & $\boldsymbol{P}$ & $\boldsymbol{R}$ \\
\hline \multicolumn{5}{|l|}{ Age } \\
\hline Attitude towards collaboration & 0.080 & -0.158 & $>0.05$ & - \\
\hline Experience in collaborative practice & 0.002 & 0.262 & $>0.05$ & - \\
\hline Role perceptions (dose adjustment) & 0.008 & 0.233 & $>0.05$ & - \\
\hline Role perceptions (dispensing prescriptions) & $>0.05$ & - & 0.30 & -0.221 \\
\hline Current collaboration (dose adjustment) & 0.002 & 0.280 & 0.12 & 0.255 \\
\hline Future collaboration (decision-making about patients' pharmacotherapy) & $>0.05$ & - & 0.017 & -0.240 \\
\hline \multicolumn{5}{|l|}{ Gender } \\
\hline $\begin{array}{l}\text { Perceived barriers to collaboration (concern about liability for shared } \\
\text { responsibility) }\end{array}$ & $>0.05$ & - & 0.000 & -0.307 \\
\hline \multicolumn{5}{|l|}{ Community size } \\
\hline Current collaboration (managing side-effects of medication) & $>0.05$ & - & 0.033 & -0.217 \\
\hline $\begin{array}{l}\text { Perceived barriers to collaboration (concern about liability for shared } \\
\text { responsibility) }\end{array}$ & $>0.05$ & - & 0.023 & -0.230 \\
\hline Perceived barriers to collaboration (lack of compensation) & $>0.05$ & - & 0.005 & 0.283 \\
\hline \multicolumn{5}{|l|}{ University affiliation } \\
\hline Attitude towards collaboration & $>0.05$ & - & 0.011 & -0.269 \\
\hline Experience of collaborative practice & $>0.05$ & - & 0.013 & 0.249 \\
\hline Role perceptions (advising on selection of over-the-counter medications) & $>0.05$ & - & 0.035 & -0.215 \\
\hline Role perceptions (managing side-effects of medication) & $>0.05$ & - & 0.006 & -0.276 \\
\hline Role perceptions (improving patient adherence) & $>0.05$ & - & 0.050 & -0.201 \\
\hline Current collaboration (dose adjustment) & $>0.05$ & - & 0.002 & -0.313 \\
\hline Current collaboration (managing side-effects of medication) & $>0.05$ & - & 0.010 & -0.262 \\
\hline Current collaboration (decision-making about patients' pharmacotherapy) & $>0.05$ & - & 0.008 & -0.268 \\
\hline
\end{tabular}

concern about "possible fragmentation of patient care by the involvement of multiple health care providers" and "lack of face-to-face communication". Neither group was overly concerned about "liability for shared information", "lack of compensation" or "dealing with multiple care professionals" as barriers to collaboration (Table 5).

\section{Discussion}

The present study provides evidence that although many pharmacists and GPs agreed on the beneficial role of collaborative practice in patient care, the majority have never tried or even considered collaboration in their professional work in the Iranian health care system. Alkhateeb et al. (19) investigated physicians' attitudes towards collaborative agreements with community pharmacists in West Virginia, United States, and found that $60 \%$ had favourable attitudes towards collaboration, although they were more inclined to collaborate in certain areas of pharmacotherapy. Kelly et al. (18) in Canada found that nearly all pharmacists and physicians had a positive attitude towards collaboration. The proportions of the two groups in our study who considered that collaboration specifically between pharmacists and GPs improves patient care were lower than in similar studies in different populations, indicating the need for further education of professionals in this regard.
The attitude towards collaborative practice was significantly correlated with the age of the pharmacists and whether they were affiliated with a university. Thus, time and experience may change attitudes. Various psychological models account for attitude change through the life cycle (20), and continuous medical education is probably influential in changing pharmacists' and GPs' attitudes. Moreover, as respondents who were actively involved in academia were more positive about collaborative practice, education may play an active role in changing attitudes.

In this study, about half the respondents in each group reported only occasional collaborative practice, consistent with the findings of two 


\begin{tabular}{|c|c|c|}
\hline Role & $\begin{array}{l}\text { Pharmacists } \\
\text { (Yes) }\end{array}$ & $\begin{array}{l}\text { GPs } \\
\text { (Yes) }\end{array}$ \\
\hline Assisting patients in selecting over-the-counter medications & $82.0 \%$ & $30.2 \%$ \\
\hline Patient counselling & $86.7 \%$ & $36.5 \%$ \\
\hline Helping to manage medication side-effects & $81.3 \%$ & $33.3 \%$ \\
\hline Helping to manage drug interactions & $82.0 \%$ & $34.4 \%$ \\
\hline Helping to improve patient adherence & $64.8 \%$ & $31.3 \%$ \\
\hline Dispensing prescriptions & $39.1 \%$ & $37.5 \%$ \\
\hline Dose adjustment & $60.2 \%$ & $20.8 \%$ \\
\hline Helping physicians to select a medication & $58.6 \%$ & $36.5 \%$ \\
\hline Helping in medication insurance and reimbursement & $35.2 \%$ & $14.6 \%$ \\
\hline
\end{tabular}

Four pharmacists and three GPS did not answer all the questions.

Canadian studies (18,21). Surprisingly, the percentage of health care providers who actually practised interprofessional collaboration in our study was higher than that with a positive attitude. Most of the respondents might have considered that collaboration among health care providers and not only between GPs and pharmacists enhances patient care.

The question remains why, despite positive attitudes towards interprofessional collaboration, both groups have experienced such limited collaborative practice. Lack of joint training courses for the two groups may have contributed. If students in both pharmacy and medicine have educational opportunities that allow for more interaction with their future colleagues, collaborative practice in health care settings may become more common. Joint activities between currently practising professionals should also be considered. Another reason for the limited collaborative experience might have been a lack of "trustworthiness", which is established by professionals who make consistent contributions to patient care and high-quality clinical recommendations that improve patient outcomes. In addition to displaying competence, both categories of professionals should ensure continuous communication to establish trustworthiness. A pre-existing relationship between a community pharmacist and a GP might also foster trustworthiness.

Pharmacists' and GPs' perceptions of the role of pharmacists in health care probably play an integral role in the establishment of collaboration. In the present study, community pharmacists considered that they had an active role in managing the side-effects and interactions of medications, assisting patients in selecting over-the-counter medications, providing patient counselling, helping to improve patient adherence and providing drug information to physicians. GPs, however, considered that the role of community pharmacists was in the more traditional areas of patient counselling and dispensing prescriptions. Our results are similar to those of other studies, which found that GPs perceive the roles of community pharmacists as supplying and dispensing medications $(22,23)$ and counselling $(24,25)$. In recent years, however, GPs' perception of the role of pharmacists has changed, with growing acceptance of a more clinical roles for pharmacists $(8,14)$. The closer the role perceptions of the two groups, the closer we come to ideal collaborative practice. We suggest

\begin{tabular}{lcc}
\hline Table 4. Pharmacists' and $\mathbf{G P s}^{\prime}$ views on areas for future collaboration & & \\
\hline Area for future collaboration & $\begin{array}{c}\text { Pharmacists } \\
(\boldsymbol{n}=\mathbf{1 3 2})^{\mathrm{a}}\end{array}$ & $\begin{array}{c}\text { General practitioners } \\
(\boldsymbol{n}=\mathbf{9 9})\end{array}$ \\
Modification of patients' pharmacotherapy & $60.3 \%$ & $38.4 \%$ \\
Dose adjustment & $60.6 \%$ & $24.2 \%$ \\
Managing side-effects of medication & $66.9 \%$ & $41.4 \%$ \\
Managing drug interactions & $67.7 \%$ & $59.6 \%$ \\
Decision-making on patients' pharmacotherapy & $77.2 \%$ & $69.7 \%$ \\
Patient counselling & $63.0 \%$ & $42.4 \%$ \\
Improving patients' adherence to medication & $54.3 \%$ & $32.3 \%$ \\
Advising on medication insurance and reimbursement & $31.5 \%$ & $21.2 \%$ \\
\hline
\end{tabular}

${ }^{a}$ Five pharmacists answered all the questions. 


\begin{tabular}{lcc}
\hline Table 5 Pharmacists and GPs' perceived barriers to collaborative practice & & \\
Perceived barrier & $\begin{array}{c}\text { Pharmacists } \\
(\boldsymbol{n}=\mathbf{1 3 2})\end{array}$ & $\begin{array}{c}\text { GPs } \\
(\boldsymbol{n}=\mathbf{9 9})\end{array}$ \\
Involvement of multiple health care professionals could fragment patient care & $64.3 \%$ & $51.5 \%$ \\
Concern about liability for shared responsibility & $42.9 \%$ & $29.9 \%$ \\
Concern about liability for shared information & $27.8 \%$ & $21.6 \%$ \\
Lack of compensation & $25.4 \%$ & $24.7 \%$ \\
Dealing with multiple health care professionals on patients' pharmacotherapy & $33.3 \%$ & $23.7 \%$ \\
Lack of face-to-face communication & $51.6 \%$ & $56.7 \%$ \\
Time-consuming & $45.2 \%$ & $40.2 \%$ \\
\hline
\end{tabular}

Six pharmacists and two GPS did not answer all the questions.

that interprofessional collaboration be taught in Iranian medical schools, as elsewhere; it is now an integral part of medical school curricula in numerous countries, including Australia, Canada, the United Kingdom and the United States $(26,27)$.

The basis of education on interprofessional collaboration is practising teamwork and building understanding of the competence, knowledge and skills of oneself and others. Collaboration other than in medical schools could also be encouraged. A number of studies have been conducted on interprofessional collaboration in medical wards. Weller et al. (28) found that organizational structures are the key to successful interprofessional practice in hospitals. In a clinical setting, members of health care teams should be able not only to clearly identify their own roles and responsibilities but also be completely aware of the competence of other team members in relation to their own (29). Policy-makers, health care managers and members of the health care system, including pharmacists and GPs, can be influential in developing interprofessional care models at both educational and institutional levels.

In this study, both respondent groups found that the current level of collaboration in all categories was low. Collaboration to manage drug interactions, provide patient counselling and manage medication side-effects was reported to be the most frequent.
Surprisingly, we found that, although only $34.4 \%$ of GPs considered that management of drug interactions was part of the role of community pharmacists, $45.6 \%$ declared that they currently collaborated with pharmacists in this area. This may be because a high percentage of pharmacists ( $82 \%)$ considered that management of drug interactions was part of their role and therefore initiated collaboration with their GP counterparts in this regard.

Both groups preferred communication by telephone and face to face rather than by fax or letter. Electronic transfer of patient information and prescriptions is not yet available in the Islamic Republic of Iran; however, a number of pharmacists commented that electronic transfer of information should be explored, as an e-prescribing system enables professionals to share patient information throughout the heath care continuum and may offer further opportunities for professionals to engage collegially.

Both groups in this study cited the main barriers to collaborative practice as "lack of face-to-face communication" and "possible fragmentation of patient care by the involvement of multiple health care providers". Kelly et al. (18) studied a population of Canadian GPs and pharmacists, who reported that lack of compensation and having to deal with multiple health care professionals were the greatest barriers to collaborative practice. In a study on barriers between community pharmacists and GPs, Hughes and McCann (17) identified the following barriers: the "shopkeeper" image of community pharmacists, limited access to both groups, hierarchy in terms of professional standing and lack of awareness of GPs about community pharmacists' level of knowledge and expertise. Once potential barriers have been identified, measures should be taken to overcome them, and pharmacists, GPs and policy-makers should all take an active role. For instance, "care coordination" could overcome fragmentation of patient care. This could involve activities such as ensuring that all health care providers involved share important clinical data and have clear shared expectations about their role in patient's care. A health plan medical team network might be a solution. Lack of face-to-face communication could be resolved by the use of cost-effective, time-saving Apps that allow video calls.

The factors gender, community size and university affiliation correlated with perceived barriers to collaborative practice. Concern about liability for shared information and responsibility was significantly correlated with the gender of the respondents, and community size was significantly related to perceiving lack of compensation and concern about liability for shared responsibility as barriers to collaboration. Different factors may be perceived as barriers in different communities. 
In order to improve our health care system and thus enhance patient care through interprofessional collaboration, we must be ready psychologically. Therefore, the psychological aspects of pharmacists' and GPs' well-being and their quality of life should be considered. It is highly probable that psychological factors play a role in hindering collaborative relationships. Dowell et al. (30) found that community pharmacists, GPs and general surgeons were among the most stressed health professionals and that they were also dissatisfied with their jobs. In a similar study conducted among Iranian community pharmacists, $78 \%$ of the participants reported satisfactory psychological and physical planes. Perceptions of general health and quality of life in a sample of community pharmacists in Tehran were found to be satisfactory (31).

One limitation of the present study was the sampling method, which was non-probability sampling. Additionally, approximately $60 \%$ of the pharmacists but only $26 \%$ of the GPs were in the youngest age group. This age effect is reflected by the pharmacists' professional life, and the study may tend to reflect mainly the ideas and perceptions of younger pharmacists.

\section{Conclusion}

Our findings support and extend the evidence on interprofessional practice between pharmacists and GPs by examining collaborative relationships between the two groups in terms of attitudes, role perceptions, experiences with collaborative practice, preferred method of communication for collaborative practice, areas of current and future collaboration and perceived barriers. The study probably has important implications for the establishment or enhancement of interprofessional practice in the Iranian health care system and indicates possible strategies for improving collaborative practice between pharmacists and GPs. For instance, we found that pharmacists and GPs agree that interprofessional collaboration among health care providers enhances patient care and outcomes; however, both groups require further education on the benefits of collaboration. Moreover, educating GPs about the roles and competence of community pharmacists will be crucial for successful collaborative practice. Multidisciplinary education of both pharmacy and GP students at undergraduate level should be encouraged to improve mutual understanding, communication and trust. Moreover, policy-makers could restructure primary health care services so that pharmacists and GPs are collocated. The results of the study can contribute to models of interprofessional collaboration, particularly between pharmacists and GPs, so that one day the model will be implemented in health care systems throughout the world and the goals of enhanced patient care and outcomes are realized. The study provides data on professional collaboration, paves the way for further studies in this area and contributes to advancement of pharmacotherapy management services, disease state management and patient care.

\section{Funding: None.}

Competing interests: None declared.

\section{References}

1. Stringer K, Curran V, Asghari S. Pharmacists and family physicians: improving interprofessional collaboration through joint understanding of our competencies. Front Pharmacol. 201312 05;4:151. PMID:24367335

2. Snyder ME, Zillich AJ, Primack BA, Rice KR, Somma McGivney $M A$, Pringle JL, et al. Exploring successful community pharmacist-physician collaborative working relationships using mixed methods. Res Social Adm Pharm. 2010 Dec;6(4):307-23. PMID:21111388

3. D'Amour D, Oandasan I. Interprofessionality as the field of interprofessional practice and interprofessional education: an emerging concept. J Interprof Care. 2005 May;19 Suppl 1:8-20. PMID:16096142

4. Van C, Costa D, Abbott P, Mitchell B, Krass I. Community pharmacist attitudes towards collaboration with general practitioners: development and validation of a measure and a model. BMC Health Serv Res. 201209 16;12:320. PMID:22978658

5. Lalonde L, Hudon E, Goudreau J, Bélanger D, Villeneuve J, Perreault S, et al. Physician-pharmacist collaborative care in dyslipidemia management: the perception of clinicians and patients. Res Social Adm Pharm. 2011 Sep;7(3):233-45. PMID:21272548

6. Kalisch LM, Roughead EE, Gilbert AL. Improving heart failure outcomes with pharmacist-physician collaboration: how close are we? Future Cardiol. 2010 Mar;6(2):255-68. PMID:20230266
7. Carter BL, Ardery G, Dawson JD, James PA, Bergus GR, Doucette WR, et al. Physician and pharmacist collaboration to improve blood pressure control. Arch Intern Med. 2009 Nov 23;169(21):1996-2002. PMID:19933962

8. Laubscher T, Evans C, Blackburn D, Taylor J, McKay S. Collaboration between family physicians and community pharmacists to enhance adherence to chronic medications: opinions of Saskatchewan family physicians. Can Fam Physician. 2009 Dec;55(12):e69-75. PMID:20008581

9. Leape LL, Cullen DJ, Clapp MD, Burdick E, Demonaco HJ, Erickson Jl, et al. Pharmacist participation on physician rounds and adverse drug events in the intensive care unit. JAMA. 1999 Jul 21;282(3):267-70. PMID:10422996

10. Cranor CW, Bunting BA, Christensen DB. The Asheville project: long term clinical and economic outcomes of a community pharmacy diabetes care program. J Am Pharm Assoc. 2003;43(2):173-84.

11. Bogden PE, Abbott RD, Williamson P, Onopa JK, Koontz LM. Comparing standard care with a physician and pharmacist team approach for uncontrolled hypertension. J Gen Intern Med. 1998 Nov;13(11):740-5. PMID:9824519

12. Sellors J, Kaczorowski J, Sellors C, Dolovich L, Woodward C, Willan A, et al. A randomized controlled trial of a pharmacist consultation program for family physicians and their elderly patients. CMAJ. 2003 Jul 8;169(1):17-22. PMID:12847034 
13. Muijrers PE, Knottnerus JA, Sijbrandij J, Janknegt R, Grol RP Pharmacists in primary care. Determinants of the care-providing function of Dutch community pharmacists in primary care. Pharm World Sci. 2004 Oct;26(5):256-62. PMID:15598065

14. Bryant LJ, Coster G, Gamble GD, McCormick RN. General practitioners' and pharmacists' perceptions of the role of community pharmacists in delivering clinical services. Res Social Adm Pharm. 2009 Dec;5(4):347-62. PMID:19962678

15. Nkansah N, Mostovetsky O, Yu C, Chheng T, Beney J, Bond CM, et al. Effect of outpatient pharmacists' non-dispensing roles on patient outcomes and prescribing patterns. Cochrane Database Syst Rev. 201007 07;7(7):CD000336. PMID:20614422

16. Hammond RW, Schwartz AH, Campbell MJ, Remington TL, Chuck S, Blair MM, et al.; American College of Clinical Pharmacy. Collaborative drug therapy management by pharmacists-2003. Pharmacotherapy. 2003 Sep;23(9):1210-25. PMID:14524655

17. Hughes CM, McCann S. Perceived interprofessional barriers between community pharmacists and general practitioners: a qualitative assessment. Br J Gen Pract. 2003 Aug;53(493):6006. PMID·14601335

18. Kelly DV, Bishop L, Young S, Hawboldt J, Phillips L, Keough TM. Pharmacist and physician views on collaborative practice: Findings from the community pharmaceutical care project. Can Pharm J (Ott). 2013 Jul;146(4):218-26. PMID:23940479

19. 19. Alkhateeb FM, Unni E, Latif D, Shawaqfeh MS, Al-Rousan RM. Physician attitudes toward collaborative agreements with pharmacists and their expectations of community pharmacists responsibilities in West Virginia. J Am Pharm Assoc (2003). 2009 Nov-Dec;49(6):797-800. PMID:19926562

20. Tyler TR, Schuller RA. Aging and attitude change. J Pers Soc Psychol. 1991 Nov;61(5):689-97. PMID:1753325

21. Pojskic N, Mackeigan L, Boon H, Ellison P, Breslin C. Ontario family physician readiness to collaborate with community pharmacists on drug therapy management. Res Social Adm Pharm. 2011 Mar;7(1):39-50. PMID:21397880
22. Bleiker $\mathrm{P}$, Lewis $\mathrm{A}$. Extending the role of community pharmacists: the views of GPs. Int J Pharm Pract. 1998;6:140-4.

23. Spencer JA, Edwards C. Pharmacy beyond the dispensary: general practitioners' views. BMJ. 1992 Jun 27;304(6843):1670-2. PMID:1633521

24. Bradshaw SJ, Doucette WR. Community pharmacists as patient advocates: physician attitudes. J Am Pharm Assoc (Wash). 1998 Sep-Oct;38(5):598-602. PMID:9782693

25. Smith WE, Ray MD, Shannon DM. Physicians' expectations of pharmacists. Am J Health Syst Pharm. 2002 Jan 1;59(1):50-7. PMID:11813467

26. Reeves S, Perrier L, Goldman J, Freeth D, Zwarenstein M. Interprofessional education: effects on professional practice and healthcare outcomes (update). Cochrane Database Syst Rev. 201303 28;3(3):CD002213. PMID:23543515

27. Reeves S, Perrier L, Goldman J, Freeth D, Zwarenstein M, Hammick M. Interprofessional education: effects on professional practice and healthcare outcomes (update). Cochrane Database Syst Rev. 201303 28;1(3):CD002213. PMID:23543515

28. Weller JM, Barrow M, Gasquoine S. Interprofessional collaboration among junior doctors and nurses in the hospital setting. Med Educ. 2011 May;45(5):478-87. PMID:21414024

29. Drinka TJK, Clark PG. Healthcare teamwork: interdisciplinary practice and teamwork. Westport (Connecticut): Auburn House; 2000

30. Dowell AC, Westcott T, McLeod DK, Hamilton S. A survey of job satisfaction, sources of stress and psychological symptoms among New Zealand health professionals. N Z Med J. 2001 Dec 14;114(1145):540-3. PMID:11833946

31. Majd M, Hashemian F, Younesi Sisi F, Jalal M, Majd Z. Quality of Life and Job Satisfaction of Dispensing Pharmacists Practicing in Tehran Private-sector Pharmacies. Iran J Pharm Res. 2012 Fall;11(4):1039-44. PMID:24250534 